\title{
Primeiro dicionário crítico de serviço social brasileiro: um processo científico revolucionário usando tics'
}

\author{
Brazilian Social Service first critic dicionary: a scientific and revolutionary process using \\ Information and Communication Technologies
}

\author{
Sarita Teresinha Alves Amaro²; Giovanni Ferreira de Farias ${ }^{3}$; Suzana De Andrade Ferreira4; \\ Michele Aguette Rodrigues; ; Daniela Refatti Simões ${ }^{5}$; Andressa Baccin dos Santos ${ }^{5}$; Ana Cláudia Carlos ${ }^{5}$ \\ I Trabalho referente ao Edital n. I7/NTE/UAB - 2012 \\ ${ }^{2}$ Assistente Social, Doutora em Serviço Social, Docente na UFSM. Consultora do Governo Federal. Pesquisadora idealizadora e coordena- \\ dora do projeto de pesquisa", financiado pela CAPES. \\ ${ }^{3}$ Engenheiro Eletrônico pela UFPB, Doutorando em EAD pela Athabasca University, Diretor da GFarias Educação Ltda. \\ ${ }^{4}$ Bacharel em Relações Internacionais. Técnica da Empresa GFarias, parceira do projeto. \\ ${ }^{5}$ Acadêmicos de Serviço Social na UFSM, Bolsistas voluntários no Projeto de pesquisa
}

\begin{abstract}
Resumo
A comunidade do Serviço Social no Brasil cresce exponencialmente. Atualmente, são mais de 100.000 assistentes sociais (portadores do titulo de bacharel em serviço social e com registro profissional ativo no pais) e mais de 800.000 estudantes de cursos de graduação e pós-graduação em serviço social. O projeto se dirige a essa comunidade. Em sua proposta, dedicou-se ao estudo e análise crítica do Serviço Social acerca de sua base fundante. Nessa perspectiva, trilhou o itinerário das origens à especificidade da profissão, convidando à reflexão sobre os componentes teórico-metodológicos, ético-políticos e técnico-operativos aludidos na história de profissionalização e legitimação do Serviço Social no Brasil. Esses componentes foram organizados através de 55 categorias temáticas, submetidas ao tratamento reflexivo-crítico dos participantes no projeto. A metodologia parte de um concurso cientifico, seguido de um rigoroso processo de análise realizado por consultores convidados, que resultará no livro "Dicionário Crítico de Serviço Social". Em todas as fases, a plataforma virtual do projeto, é ferramenta central e facilitadora, ensejando a construção conceitual, a experiência coletiva e colaborativa proposta e, especialmente, superando distâncias geográficas (as quais direta ou indiretamente acabam reforçando desigualdades regionais e a centralização de saberes). $\mathrm{O}$ projeto intenciona compor rompimentos com os lugares de saber e poder instituídos, portanto. O uso de tecnologia de informação e comunicação como metodologia faz parte do olhar inovador e contemporâneo que marca o projeto. Complementarmente, também se inova ao convidar à construção da obra dicionário crítico, estudantes e profissionais de serviço social, do âmbito do trabalho e da academia, aposentados ou ativos em sua atividade ocupacional, nas múltiplas atuações e representações no terreno da profissão. É para partilhar essa experiência e significá-la que apresentamos esse artigo.
\end{abstract}

Palavras-chaves: serviço social - fundamentos - conceituação - conhecimento cientifico - tecnologias de informação e comunicação (TICs)

\begin{abstract}
The community Social Work in Brazil is growing exponentially. Currently are more than 100,000 social workers (carriers title's degree in social work and active with professional registration in the country) and over 800,000 students in undergraduate and graduate social work. The project addresses this community. In his proposal, he devoted himself to the study and critical analysis of Social Work about its founding basis. From this perspective, the route trod origins of the particular profession, inviting reflection on the components theoretical and methodological, ethical-political and technical-operative alluded in the history of professionalization and legitimization of Social Work in Brazil. These components were organized through 55 thematic categories, subjected to critical-reflective treatment of the participants in the project. The methodology part of a scientific contest, followed by a rigorous review process conducted by consultants invited, resulting in the book "Critical Dictionary of Social Work." At all stages, the virtual design platform, is central tool and facilitator, allowing for the construction concept, the collective experience and collaborative proposal and especially overcoming geographical distances (which directly or indirectly end up reinforcing inequality and regional centralization of knowledge). The project intends to compose disruptions to the places of knowledge and power in place, so. The use of information and communication technology as a methodology, is part of the innovative look and contemporary brand design. In addition, it also breaks new ground by inviting the construction work of critical dictionary, students and professionals in social work, scope of work and academia, retired or active in their occupational activity in multiple performances and field offices of the profession. It is to share this experience and meaning it we present this article.
\end{abstract}

Keywords: social work - fundamentals - concepts - scientific knowledge - information technology and communication (ICT) 


\section{INTRODUÇÃO}

O Brasil tem vivenciado um processo de consolidação e ampliação de direitos sociais, forjado no confronto entre um movimento retrógrado - conservador de manutenção da desigualdade e do poderio de pequenas elites com o seu oposto, a ação crítico-política, de viés renovador e de mudança, acionada pela organização da sociedade civil, na forma de intensas e articuladas lutas sociais.

Nesse contexto, edificou-se a constituição cidadã de 1988, a seguridade social que temos e, sob seu manto, a política de assistência social, tão cara aos segmentos empobrecidos.

O serviço social é um dos principais protagonistas dessa história de lutas por direitos sociais e por políticas públicas mais justas e afirmativas no país. Mais que isso: a história do serviço social é permeada por processos profissionais que têm ressonância direta nos processos sociais, especialmente aqueles que incidem na ampliação da cidadania dos segmentos tradicionalmente excluídos.

A comunidade do serviço social no Brasil vem crescendo exponencialmente, reafirmando-se na sociedade, atuando em diferentes frentes para garantir e ampliar direitos, participando ativamente do processo de construção do Estado democrático de direito. Em 2011, haviam 108.893 assistentes sociais inscritos ativos ${ }^{1}$ e, segundo dados do MEC, em 2012 existiam mais de 500.000 estudantes de serviço social distribuídos em mais de 400 cursos de graduação autorizados (presenciais ou Ead) no país.

Complementarmente, cresce exponencialmente também a comunidade da pós-graduação em serviço social. Só para se ter uma ideia, segundo informações da CAPES ${ }^{2}$, atualmente temos 31 (trinta e um) programas de pós-graduação stricto sensu (mestrado e doutorado) em serviço social ativos no pais. Estes formam os bancos de pesquisadores na área profissional e influenciam diretamente no aumento significativo da produção científica do serviço social. Em pesquisa a dados da Plataforma Lattes do $\mathrm{CNPq}^{3}$, apenas consi-

\footnotetext{
1 De acordo com informações do Conjunto CFESS/CRESS, com base em setembro de 2011. Disponível em: http://www.cfess.org.br/arquivos/relatoriofinal 40NACIONAL. pdf. Acesso em:25/07/2012.

2 Fonte: CAPES. Disponível em: http://conteudoweb.capes.gov. $\mathrm{br} /$ conteudoweb/ProjetoRelacaoCursosServlet?acao=pesquisarI es \& codigoArea $=61000000 \&$ descricaoArea $=\mathrm{CI} \% \mathrm{CANCIAS}+\mathrm{SO}$ CIAIS+APLICADAS $+\&$ descricaoAreaConhecimento $=$ SERVI $\%$ C7O+SOCIAL\&descricaoAreaAvaliacao $=$ SERVI\%C7O+SOCIAL Acesso em 27/07/2012

3 Fonte: CNPq. Disponível em: http://dgp.cnpq.br/buscagrupo/. Acesso em 29/07/2012.
}

derando os pesquisadores que constam na base do Diretório de Grupos de Pesquisa (ref. Censo 2010), tem-se o número de 344 pesquisadores de serviço social, a maioria vinculada, a dois grupos de pesquisa, em média.

O que esses dados quantitativos revelam é o adensamento da qualidade científica do conhecimento profissional e sua forte ressonância no terreno da formação.

O serviço social (...) vem redimensionando radicalmente sua imagem social e hoje é reconhecido no plano acadêmico como área de produção de conhecimento, interagindo paritariamente com as ciências sociais e intervindo ativamente no plano da formulação das políticas públicas (Netto, 2005, p. 18)

Mas o avanço do serviço social não se restringe ao âmbito acadêmico:

No mercado de trabalho, crescem os postos de trabalho (em diversidade) e nestes o número de vagas para assistentes sociais; tornando o profissional de serviço social cada vez mais requisitado, tanto nas corporações privadas, como nos órgãos públicos (Amaro, 2013)

Cada vez mais o assistente social tem sido referenciado nas ciências sociais como um profissional estratégico à tessitura de um novo, mais humanizado e socialmente justo mundo social:

O serviço social brasileiro desenvolveu-se na pesquisa acerca da natureza de sua intervenção, de seus procedimentos, de sua formação, de sua história e, sobretudo, acerca da realidade social, política, econômica e cultural onde se insere como profissão na divisão social e técnica do trabalho. Avançou na compreensão da questão social, do Estado capitalista, das políticas sociais, dos movimentos sociais, do poder local, dos direitos sociais, da cidadania, da democracia, do processo de trabalho e de suas transformações, da realidade institucional, das múltiplas faces da exclusão social e da pobreza e de outros temas. Obteve o respeito de seus pares no âmbito interdisciplinar e alcançou a visibilidade na interlocução com as ciências sociais (Yazbek \& Silva, 2005, p. 30) 
Esse itinerário, no entanto, na mesma medida em que referencia a legitimação social da profissão na contemporaneidade, também apresenta constantes desafios ao serviço social e exige do profissional a construção de respostas profissionais eticamente coerentes, teoricamente consistentes e tecnicamente competentes.

Esse duplo condicionamento, acentua o Serviço social como uma profissão necessária e estratégica a sociedade contemporânea, e que, exatamente por isso, requisita um permanente e critico olhar para guiar sua atuação na sociedade - iluminado pela direção apontada em seu Projeto ético-político e alinhado às demandas da própria sociedade brasileira, sobretudo a que vive em situação de vulnerabilidade e desigualdade social.

Para agir nessa direção, contudo, o profissional precisa guiar-se. Como bússola, conta com os pilares profissionais, dentre os quais estão a lei de regulamentação da profissão, o código de ética profissional e uma intensa produção cientifica (Amaro, 2013). Conta também com uma formação profissional, de nível superior, alicerçada em padrões de qualidade curriculares, construídos e consolidados conjuntamente por várias representações coletivas da profissão. Como síntese desse processo, tem-se uma formação profissional, cuja base ético-teórico-metodológica favorece a composição de um profissional crítico, propositivo, criativo e competente, ou seja, dotado de qualidade técnica e política, para articular, mobilizar, promover, organizar e apoiar processos de resistência social e luta por cidadania, potenciando as forças das minorias e segmentos excluídos.

O perfil apontado, contudo, enquanto constructo histórico de uma categoria profissional consolidada há mais de 70 anos no País, nem sempre pode ser apreendido na imediaticidade ou sem aprofundamento teórico-crítico. O oficio profissional, plasmado à materialidade da vida social e reprodução da vida cotidiana (especialmente dos sujeitos que buscam atenção aos seus direitos), edifica-se historicamente na mediação ativa, propositiva e competente nos processos de trabalho que organiza e desenvolve.

Isso remete à produção do conhecimento profissional, forjada na formação acadêmica, especificamente no terreno da pós-graduação, sintetizada em uma colossal produção de literatura especializada, sobretudo nos últimos vinte anos. $\mathrm{O}$ vasto material, contudo, não parece assegurar uma práxis necessariamente critica e segura do oficio profissional. Ou seja: há segmentos profissionais, mesmo experientes, que se ressentem da falta de subsídios para posicionar-se profissionalmente, a começar pelo efetivo domínio dos componentes teórico-discursivos da profissão, obstáculo que se revela, evidentemente, no trabalho profissional produzido. Marilda Iamamoto reflete sobre esse obstáculo em uma de suas obras:

A interação entre o aprofundamento teórico rigoroso e a prática renovada, politicamente definida, constitui elemento decisivo para superar as artimanhas ideológicas, incorporadas pela profissão em sua evolução histórica: o voluntarismo, a prática rotineira e burocratizada, as tendências empiricistas, o alheamento central do modo de vida do povo e o desconhecimento do saber popular. O posicionamento crítico - que passa a ser assumido nos últimos anos por uma parcela minoritária, embora crescente, de assistentes sociais - emerge não apenas de iniciativas individuais, mas como resposta possível às exigências apresentadas pelo momento histórico (Iamamoto, 1992, p. 37)

A recusa do pragmatismo e teoricismo estéreis, bem como a negação da cultura fatalista e messiânica (Iamamoto, 1999, 2001) que, por longo tempo, reificaram a consciência dos assistentes sociais, associadas à superação da alienação (Martinelli, 2000) constituem um processo de ruptura com a herança conservadora, que o serviço social tem aprendido a construir na dialética do seu cotidiano e história.

Essa preocupação não é ocasional ou pontual, mas é histórica e assinala tanto uma lacuna de conhecimento, como uma inadiável necessidade de enfrentá-la.

A questão que se coloca é que, apesar da efervescência e inquestionável contributo teórico do universo das obras existentes, estas nem sempre existem em diálogo e organicidade, muitas vezes por diferenças temporais e teóricas, dificultando a construção de um marco teórico conceitual, consoante com o atual paradigma critico, renovado e emancipatório adotado pela área nesse milênio.

Expressões como "intervenção" profissional, "prática profissional" e "processos de trabalho" são um exemplo dessa situação, que requisita a observação de seus marcos histórico-temporais específicos para serem devidamente compreendidas, sob pena de margear o senso comum e lugares teórico-discursivo já superados pela profissão, na contemporaneidade. Outras expressões, necessárias à atuação dos assistentes sociais nas políticas sociais, como os conceitos de "família", de "desenvolvimento social", de 
"assistência social", de "vulnerabilidade social", de "pobreza/empobrecimento", de "cidadania", e não raro, de "serviço social" e, mais recentemente, de "serviço social crítico" têm a mesma pertinência.

O desconhecimento ou incerteza do sentido teórico-conceitual dessas expressões, não apenas retarda a compreensão analítico-crítica do repertório profissional, mas efetivamente divorcia o profissional de sua competência na contemporaneidade, no compasso em que ao fragilizar seu discurso, fragiliza também sua "prática discursiva" Ou seja:

as respostas que organiza revelam, por essência, o discurso e o que o conforma como tal: seus vazios, retrações, imprecisões e assujeitamentos.

Em atenção a essa realidade e seus condicionantes, bem como com a vontade de contribuir a sua superação, desenvolveu-se o projeto de pesquisa "Dicionário critico de serviço social: construção de categorias e conceitos fundamentais ao serviço social contemporâneo", o qual foi coordenado pela Prof Dra, Sarita Amaro e promovido pela Universidade Federal de Santa Maria (UFSM), com o apoio da CAPES.

O projeto, aprovado no Edital 17/2012 da Universidade Aberta do Brasil na Universidade Federal de Santa Maria (UAB/UFSM), volta-se a esse desafio: arregimentar e mobilizar estudos, (re)conceituações e revisões na literatura cientifica especializada do serviço social, no sentido de compor um conjunto orgânico, crítico e atualizado do conhecimento profissional, forjado por um processo colaborativo de construção coletiva, usando tecnologias de informação (TICs) e recursos da educação on line, cujo produto final será a organização de um texto referencial e norteador, na forma do primeiro dicionário critico da profissão no Brasil.

\section{METODOLOGIA}

A experiência de construção coletiva de saberes e conhecimentos em plataformas colaborativas é um processo cada vez mais presente

\footnotetext{
4 Evidentemente, nesse comentário a referência ao discurso que fazemos se baseia no modo como o analista Michel Foucault entende o discurso. Foucault colabora no entendimento do discurso como "pratica discursiva", como revelador da verdade, da ética, dos valores e das relações. Os discursos, explicitam a gênese dos processos e dos sujeitos nesses processos. Para o autor, o discurso não é meramente textual ou verbal, é prática discursiva, materializado e corporificado em ações, atitudes, gestos ,sendo as conceituações, verbalizações e textualidades, (na superfície) apenas algumas de suas manifestações.
}

na contemporaneidade, o qual guarda relação direta e orgânica com os princípios de democracia e emancipação social, dado que é forjado por uma construção discursiva em que sujeitos estão abertos à troca, à intersubjetividade e ao diálogo com outros sujeitos - manifestos em suas vozes, interesses e valores específicos. Existe uma gama variada de Plataformas para Colaboração em Rede: dentre as quais estão plataformas de resgate; plataformas para ação popular; Plataformas para comércio; plataformas voltadas ao empoderamento social e local e, as mais comuns, plataformas na área da educação.

$\mathrm{Na}$ área educacional destaca-se o Wiki. Ferramenta de escrita colaborativa onde exercita-se a coautoria como forma de avançarmos em relação a simples contribuição individual e "evoluirmos" para a colaboração aberta e democrática. Um exemplo de Wiki que podemos citar na área acadêmica é a Wikipedia, uma enciclopédia virtual composta colaborativamente em nível mundial e que é bastante consultada por públicos de todas as idades, níveis sociais e culturais, e que possibilita o acesso a hipertextos e a intertextos que respondem ao nível de indagação e aprofundamento de cada interlocutor.

Mesmo que o projeto não tenha as mesmas características operacionais de uma construção colaborativa on line, como o wiki, nem apresente seus resultados e constructos como se faz na Wikipédia (com acesso a hipertextos e intertextos), o fato de guiar-se pelos mesmos valores e princípios comandou todo o processo de conhecimento investido, ao: 1. interferir nas ações de seus protagonistas (colocando-os "em colaboração"); 2. instaurar uma cultura cientifica assentada na democratização dos saberes e dos processos que os produzem; 3. promover uma extraordinária mobilização da comunidade profissional convidando-a a uma construção colaborativa, de dimensão nacional.

A metodologia que realizou esse intento partiu de um concurso científico, a saber, o Concurso Nacional de Conceituação de Categorias Fundamentais ao Serviço Social Brasileiro Contemporâneo que, seguida de um rigoroso processo de análise realizado por consultores convidados, resultou na edição do livro "Dicionário Crítico de Serviço Social", o primeiro livro dessa natureza na história da profissão no Brasil.

No caminho eleito, trilhou-se o itinerário das origens à especificidade profissional, refletindo sobre os componentes teórico-metodológicos, ético-políticos e técnico-operativos, aludidos na história da profissionalização e legitimação do Serviço Social no Brasil. 


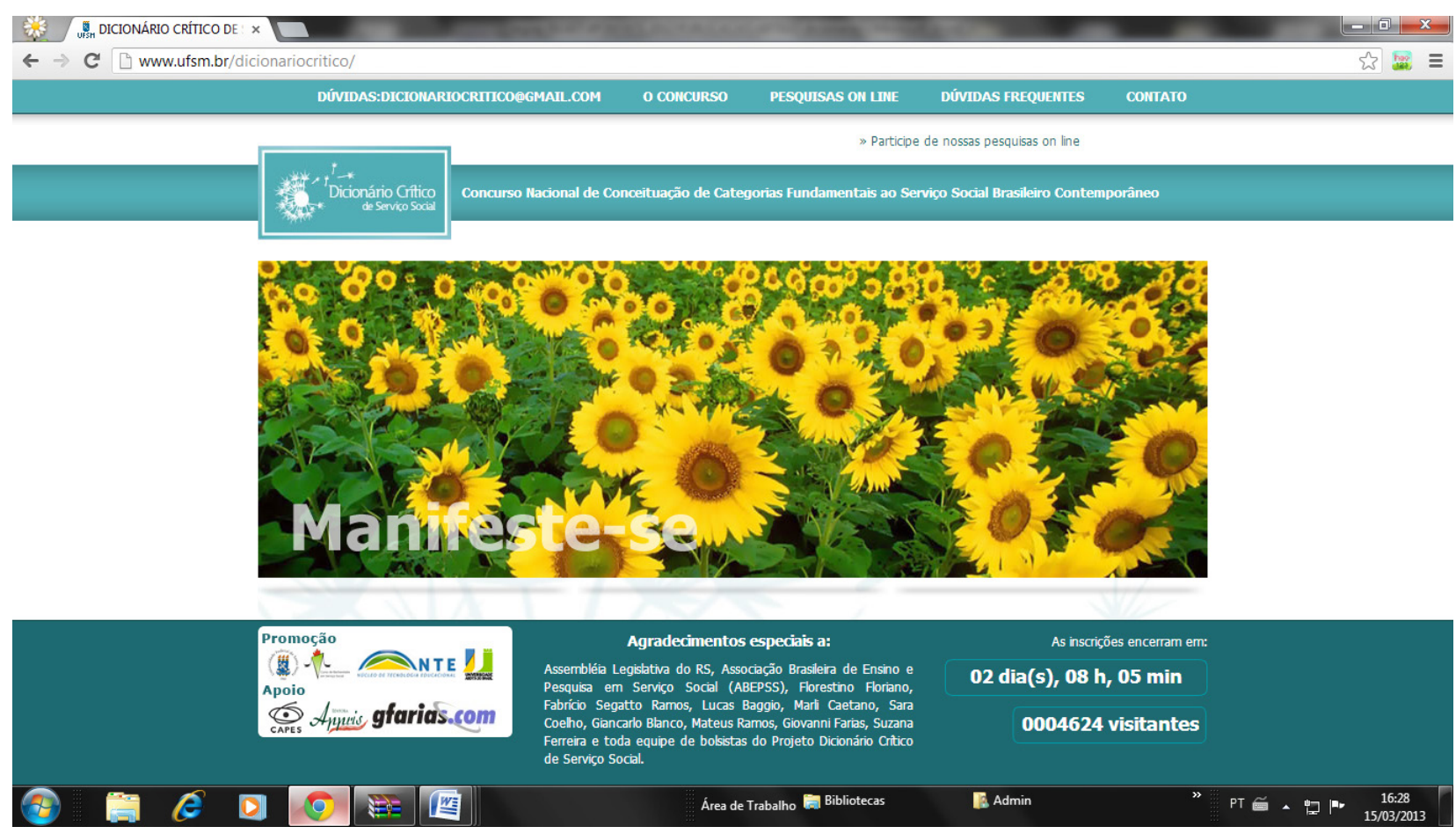

Figura 1 - Página principal do projeto na internet

Fonte: www.ufsm.br/dicionariocritico

Esses componentes foram organizados através de 55 categorias temáticas (minuciosamente selecionadas atentas às temáticas mais relevantes à profissão ao longo de sua história $\mathrm{e}$ que se refletem na contemporaneidade), as quais foram submetidas ao tratamento reflexivo-crítico dos sujeitos partícipes no projeto.

Em todas as fases, o uso de tecnologias de informação e comunicação (TICs) e dos recursos da educação on line, por meio da plataforma virtual do projeto (site principal $^{5}$ e ambiente moodle), foi central à produção da construção conceitual proposta.

Para lidar com múltiplas competências necessárias no trato de um projeto de natureza das ciências sociais, mas estruturado operacionalmente em TICs, a coordenação optou por um estilo de liderança distribuída (Write, 2008), onde uma equipe multidisciplinar procurou as melhores soluções em suas respectivas áreas, baseados no entendimento do contexto de uso de TICs para viabilização do projeto.

Foram consideradas questões legais relacionadas a Direito Autoral ${ }^{6}$ e autoria e coautoria

\footnotetext{
5 Na figura 1, tem-se uma visão recente do site do projeto, já a poucos dias do término das inscrições, com uma visitação expressiva de mais de 4600 visitantes únicos. "

6 Sobre isso, é interessante comentar que além de estar atenta à legislação especifica sobre direito autoral, a coordenadora do projeto, ao longo de três meses, simultâneos à execução do projeto, participou do curso
}

em ambientes virtuais, questões tecnológicas rela cionadas com infraestrutura de servidores para atender ao projeto, bem como questões de design, haja visto que o projeto tinha que se apresentar adequadamente na web, tanto do ponto de vista estético quando do ponto de vista de usabilidade de interface do usuário.

Evidentemente, isso demandou um trabalho hercúleo de todos os envolvidos e, mais expressivamente, da coordenação e da equipe de bolsistas atuantes no projeto.

Nos bastidores desse processo, computa-se o trabalho intenso, tanto individual como em minigrupos, da coordenação e bolsistas, engajados em atividades estratégicas relacionadas ao desenvolvimento do projeto, correntemente organizadas por meio de reuniões sistemáticas, em que a cultura colaborativa, construtiva e dialogal, própria de um processo autêntico e democrático de cogestão, foi a tônica ${ }^{7}$.

\footnotetext{
"Autoria e co-autoria em ambientes virtuais de ensino-aprendizagem" com carga horária de 60h, promovido pelo Núcleo de Tecnologia Educacional (NTE) e pela Universidade Aberta do Brasil na Universidade Federal de Santa Maria (UAB/UFSM), no âmbito do Programa Anual de Capacitação Continuada (PACC 2012) da DED/Capes, em que pode reunir subsídios e informações adicionais acerca de processos colaborativos de autoria em ambientes virtuais, a fim de guiar a operacionalização da publicação do livro, decorrente do projeto.

7 Só para se ter uma idéia, houve semanas em que o número de reuniões da coordenação com a equipe integral dos bolsistas e com as
} 


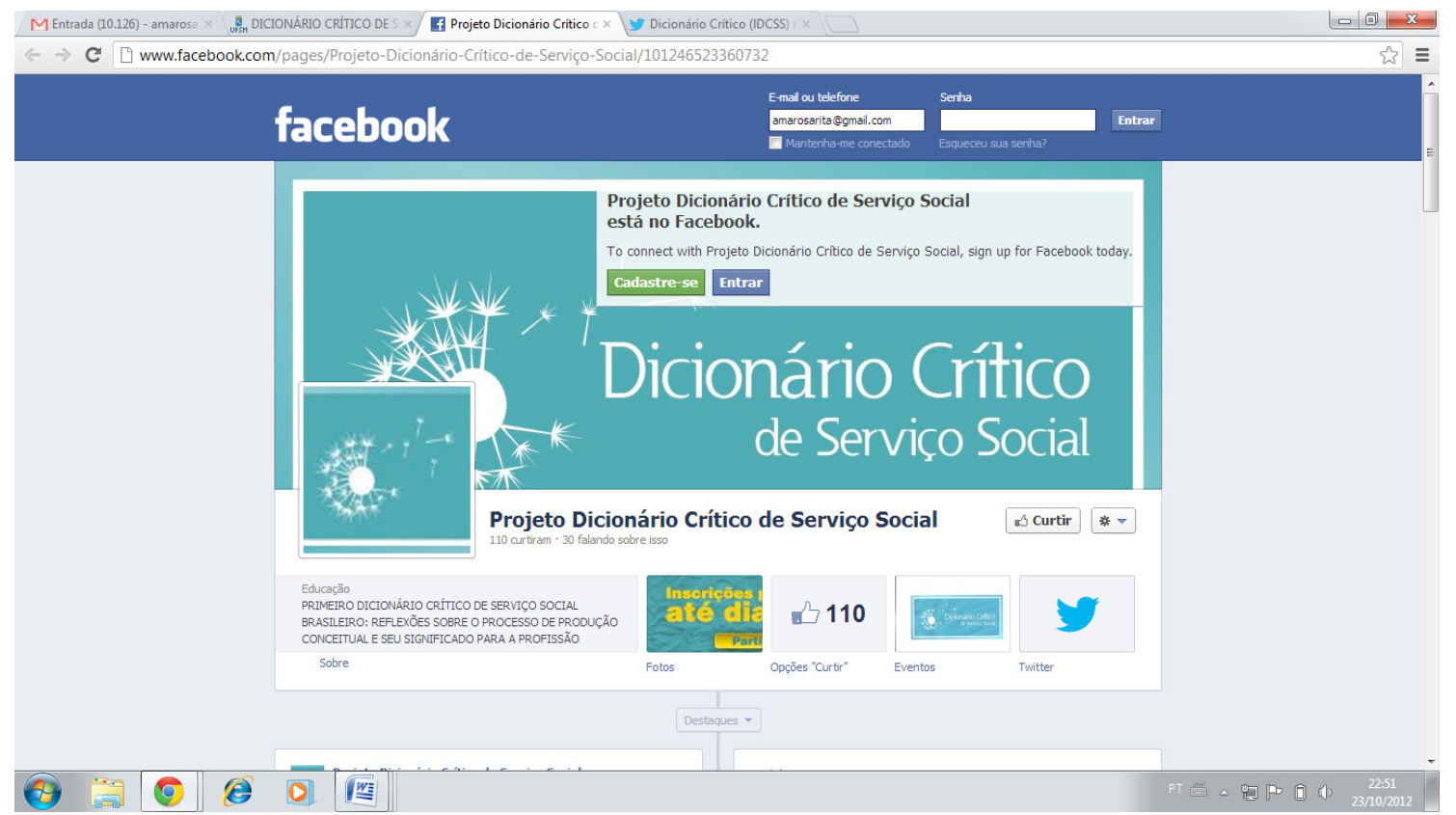

Figura 2 - Página do projeto no facebook

O diálogo e a complementação de saberes, o processo decisório democrático e ao mesmo tempo a construção criativa e coletiva vivenciadas, na medida em que eram valorizados como cultura de trabalho pela coordenação, implicavam positivamente na qualificação da equipe, no empoderamento pessoal, no aprimoramento acadêmico e, nessa práxis, potenciavam o êxito das atividades desenvolvidas no projeto, como um todo.

Guiados por essa mesma dialógica, buscou-se intensificar a comunicação do projeto com a comunidade profissional e acadêmica, foco do projeto. Atender a essa atividade, enquanto estratégia de publicidade e difusão do projeto, requisitou um intenso trabalho da equipe de bolsistas, voltado à pesquisa e construção de mala direta da comunidade profissional e envio de informes, convites noticiando o concurso, endereçados a mais de 10 mil emails relacionados.

A difusão do projeto nas redes sociais (como pode ser verificado nas Figuras 2, 3 e 4) demonstra parte desse trabalho.

Assim que os participantes tomavam conhecimento do concurso e de seu regulamento próprio por meio das mídias e publicidade produzidas, acessavam o site principal do projeto (apresentado anteriormente na Figura 1), em que o concurso era apresentado. Seqüencialmente, ao avançar nas páginas do projeto, quando buscavam

micro equipes de trabalho constituídas, ocupava cerca de $20 \mathrm{~h} / \mathrm{sema}$ nais - isso sem contar o tempo individual investido na execução das atividades regulares de desenvolvimento, monitoramento e avaliação. informações pormenorizadas acerca do processo de inscrição propriamente dito, os visitantes eram redirecionados à plataforma moodle, onde além de obter informações detalhadas, efetuavam sua inscrição no concurso, apresentando sua produção conceitual relativa à(s) categoria(s) temática(s) de sua escolha (dentre as 55 apresentadas no concurso, conforme regulamento do concurso).

Neste contexto, a considerar que a coleta de dados ocorreu no cenário das inscrições de conceituações ao concurso, a tecnologia escolhida para executar o processo investigativo usou o Moodle (Modular ObjectOrientedLearningEnvironment). Apesar de se tratar de um ambiente virtual de aprendizagem, o Moodle é modular e conta com configuração flexível o suficiente para ter múltiplos usos, inclusive o de coleta de trabalhos via Internet. A página inicial da solução web baseada em Moodle é mostrada na Figura 5.

No processo de inscrição de trabalhos, o participante precisava se cadastrar, por meio do preenchimento de um formulário especifico e, posteriormente, aceitar os termos de participação do projeto, para então poder ter acesso ao mecanismo de inscrição de trabalhos; como mostrado na Figura 6. A partir da aceitação dos termos de participação do projeto, o acesso ao formulário de inscrição de trabalhos, era "liberado", conforme é apresentado na Figura 7.

Uma vez na página do formulário, o participante determinada um título para o trabalho e, no campo com editor de texto WYSIWYG 


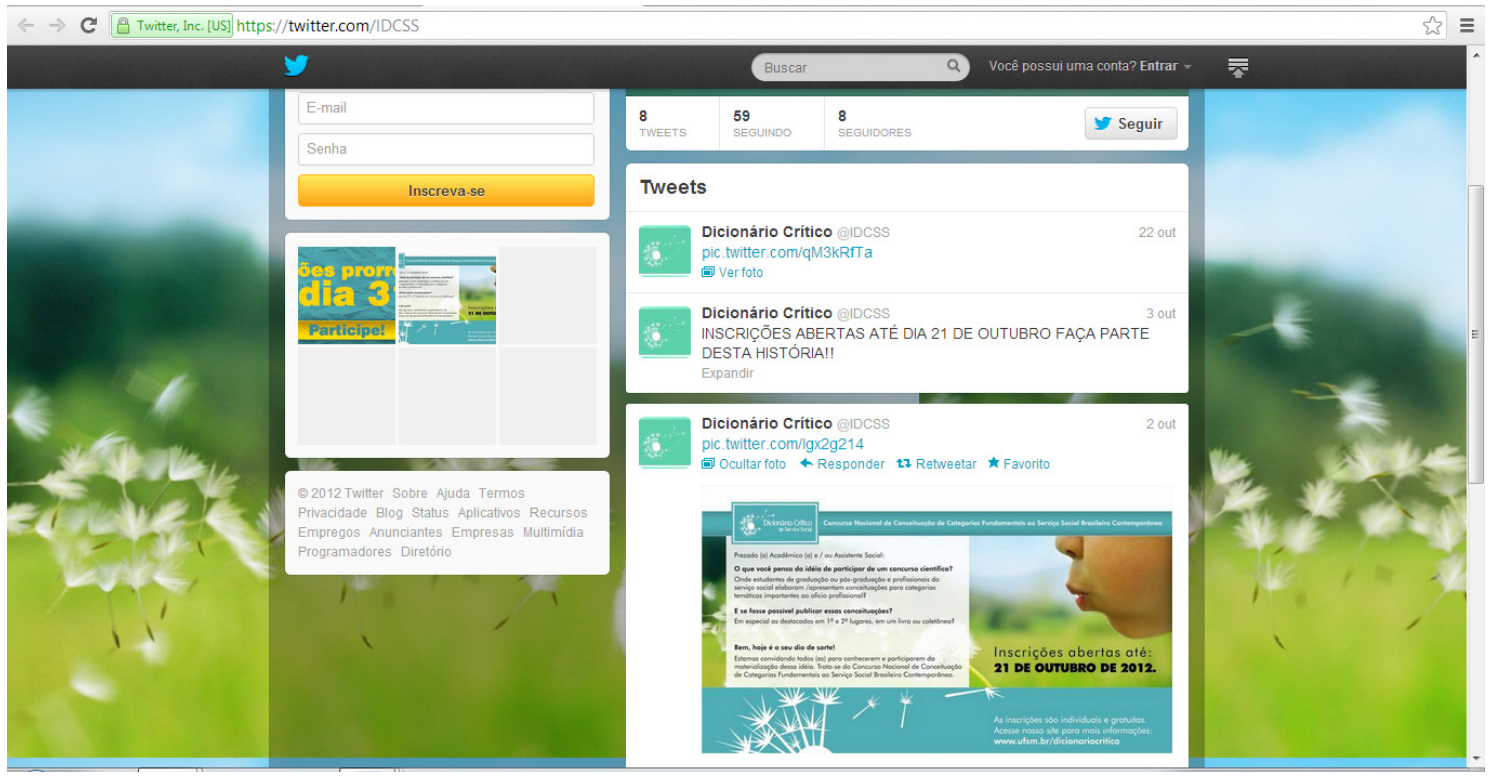

Figura 3 - Página do projeto no twitter

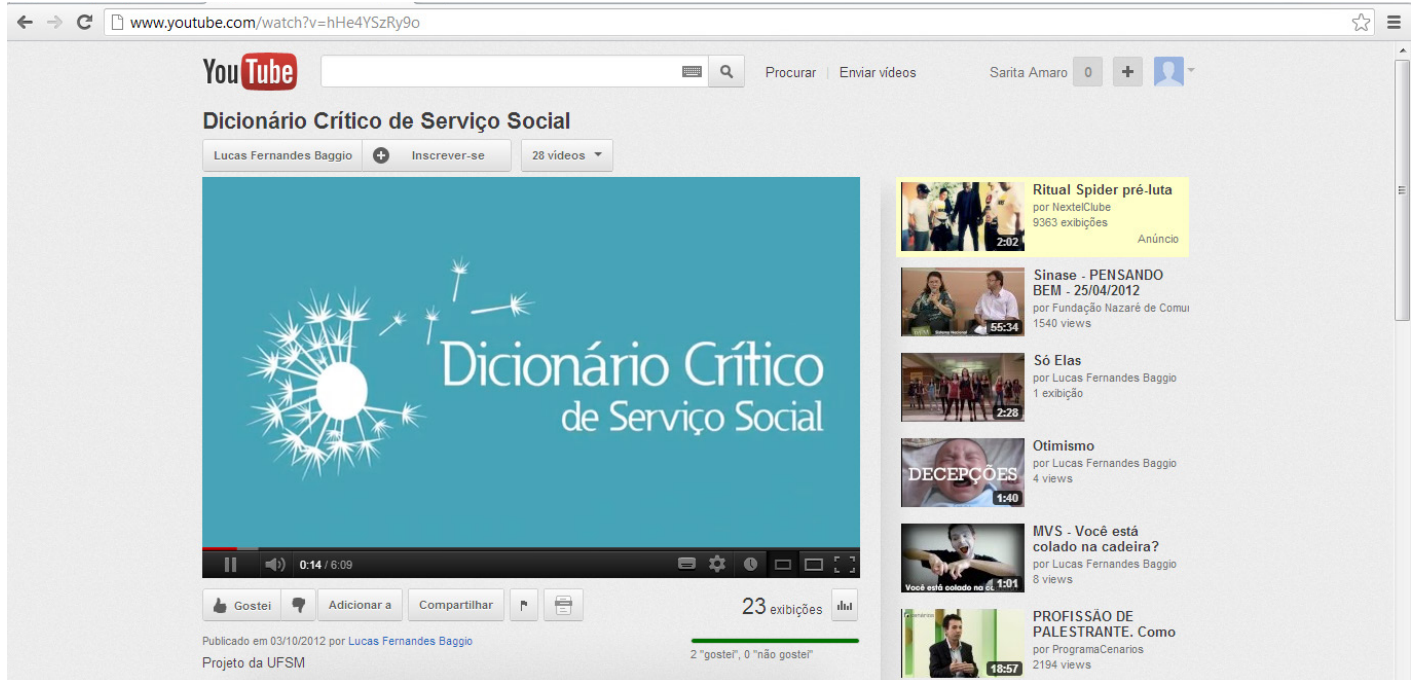

Figura 4 - Vídeo do projeto do you tube
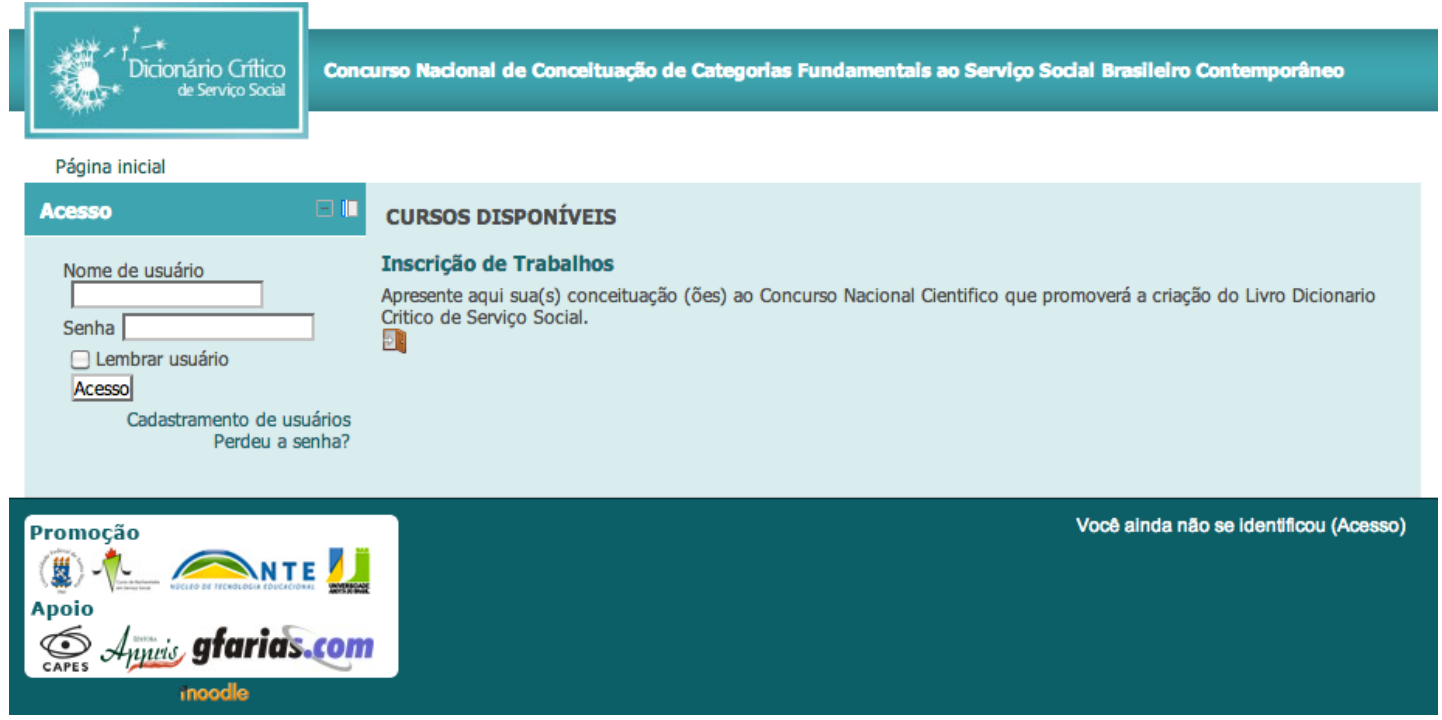

Figura 5 - Página inicial do ambiente moodle do concurso 
| Português - Brasil (pt_br) |

Página inicial \Meus cursos \ Inscrição de Trabalhos

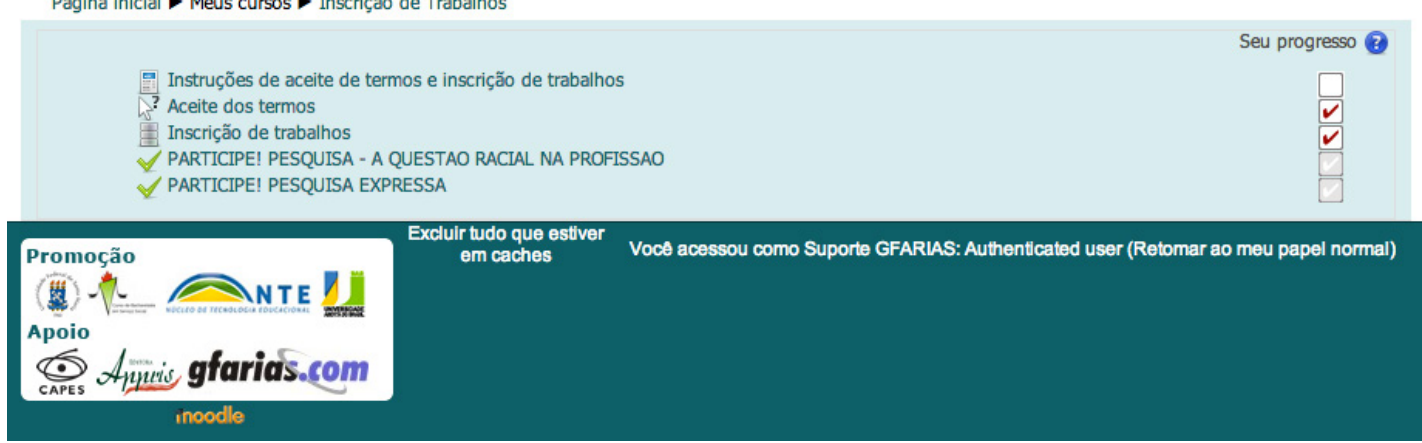

Figura 6 - Página de apresentação dos recursos web usados para inscrição no concurso

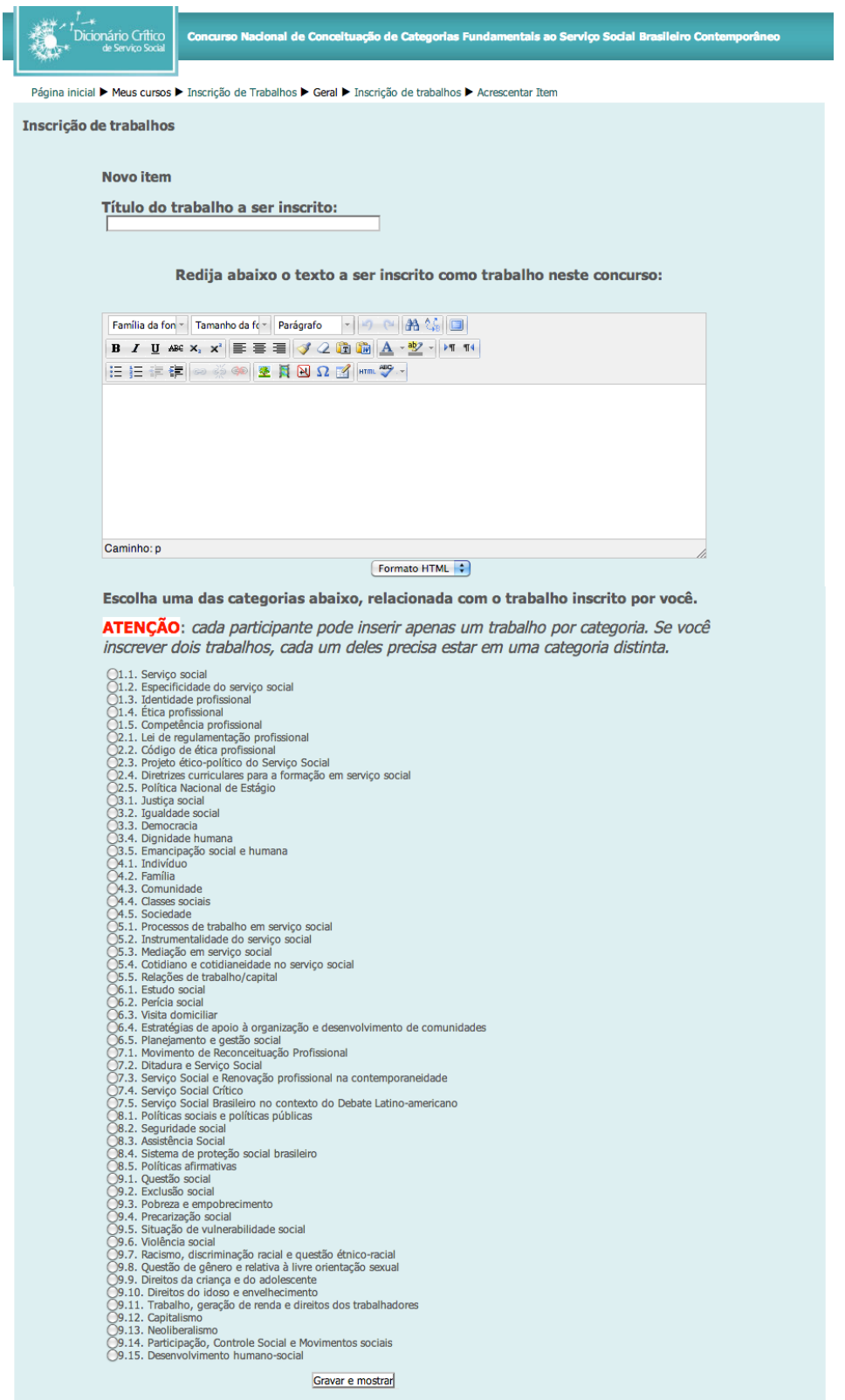

Figura 7 - Formulário de inscrição de trabalho 


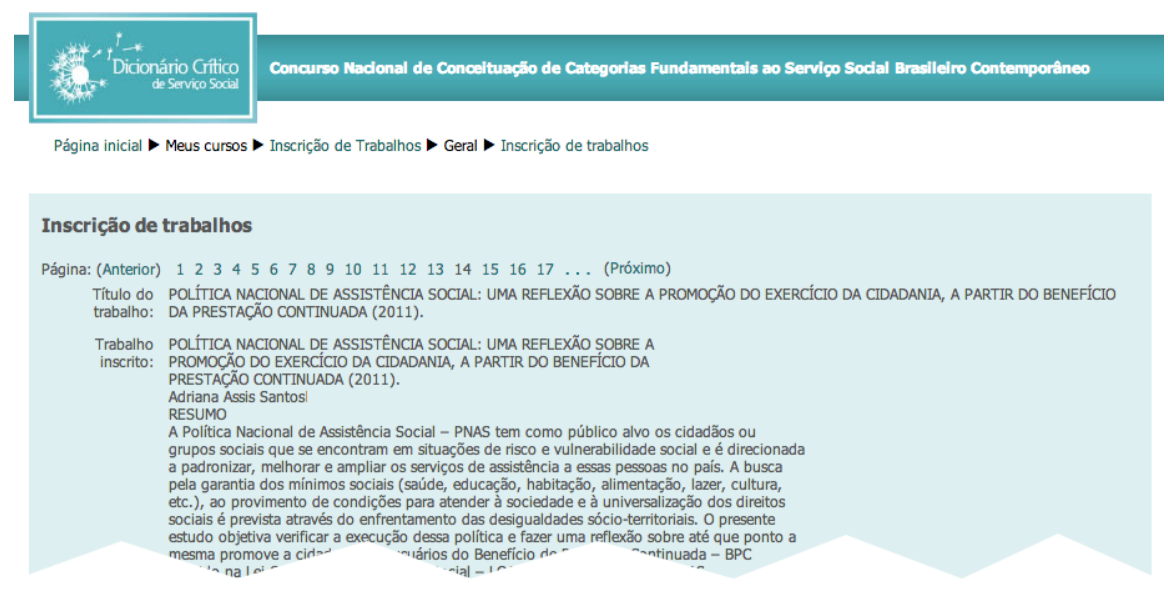

Figura 8 - Visualização de um trabalho submetido ao concurso

(WhatYouSee Is WhatYouGet), inseria o conteúdo do trabalho propriamente dito. Finalmente, escolhia uma categoria à qual o trabalho estaria relacionado para submetê-lo clicando no botão "Gravar e Mostrar".

O trabalho submetido, após esse passo-a -passo, poderia ser visto pela administração do projeto, já em seu formato web, como é mostrado na Figura 8.

Além de servir a inscrição de trabalhos, a plataforma virtual do projeto, serviu também ao monitoramento do processo como um todo, desde a administração do site até a comunicação entre equipe e participantes, principalmente no caso de esclarecimentos de dúvidas (como no link fale conosco / contato) as quais puderam ser realizadas usando o próprio site principal e/ou ambiente Moodle.

Os trabalhos submetidos referentes às conceituações recebidas no concurso, após o término das inscrições recebiam o tratamento analítico da pesquisadora (coordenadora) e equipe de apoio (comissão organizadora) do projeto. Elegeu-se para isso a análise de conteúdo de Bardin (1979). A análise de conteúdo (AC) tem uso corrente nas análises de produções textuais e comunicações, em especial, das ciências humanas e sociais. Autores como Minayo (2000) e Trivinos (1987) defendem que a análise de discurso visa ultrapassar o nível do senso comum e o subjetivismo na interpretação de textos.

Essa fase foi importante para conferência dos textos, verificando se estavam adequadas à formatação informada no regulamento, além da submissão dos textos ao programa "rastreador de plágio". Estas ações serviram também para organizar os textos por categoria temática e gerenciar o seu encaminhamento à análise dos pareceristas, consultores experts em serviço social, especialmente convidados pela pesquisadora/coordenadora do projeto, para formarem a comissão avaliadora do concurso.

As conceituações, destacadas/selecionadas no processo de análise e avaliação do concurso, por regra, integraram o conteúdo do livro - intitulado "Dicionário Crítico de Serviço Social", conforme Figura 9.

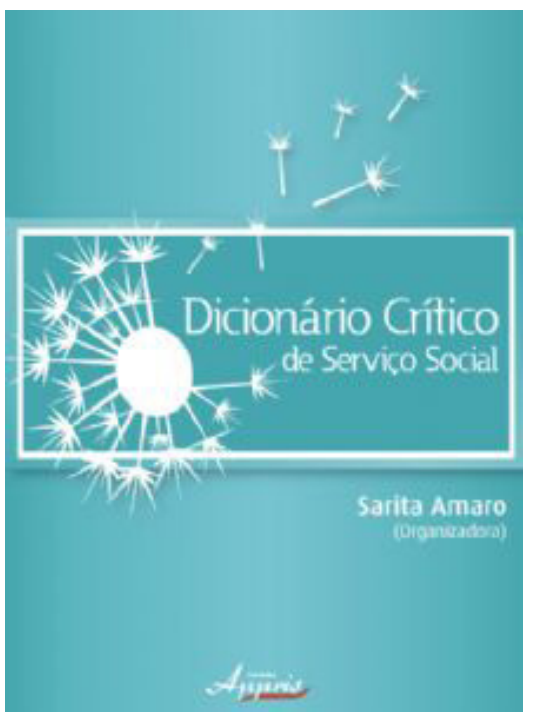

Figura 9 - Capa do livro resultante do projeto/concurso

\section{RESULTADOS E DISCUSSÃO}

Desde sua idealização, o projeto aspirava realizar um processo de conhecimento crítico, coletivo e colaborativamente organizado. Ao deflagrar esse processo, pelas qualidades imantadas pelo mesmo, convidou a ampla comunidade profissio- 
nal do serviço social brasileiro a uma atualização/ revisão científica e crítica sobre seus fundamentos.

A produção (em andamento) do livro dicionário responde a uma necessidade contemporânea e tem ampla ressonância na profissão, no compasso em que permeia a formação profissional e produção científica, em todos os níveis, e deixa uma contribuição para as gerações presentes e futuras.

$\mathrm{O}$ fato de o dicionário ser escrito a varias mãos, por pesquisadores com expertise nos temas que desenvolvem, cujos textos foram selecionados por consultores altamente especializados, reitera o exponencial valor de seu contributo, amplo dimensionamento e marcante repercussão na profissão.

O projeto criou uma oportunidade para o assistente social contemporâneo dizer quem é, o que pensa, quais são suas bases e luzes, em uma genealogia que visa a quebra de assujeitamentos, obstáculos e retrações políticas. Nessa direção, mobilizou gerações de assistentes sociais, pesquisadores e estudantes de diferentes níveis de ensino e aprofundamento.

Mas é bom que se diga: não apenas o produto final, o livro dicionário, mas o processo em que o mesmo se edifica, foi marcantemente importante e significativo.

O primeiro e imediato aspecto que refere o extraordinário dessa experiência foi além de ter superado as barreiras espaciais e geográficas, por meio do uso das TICs, tê-lo empreendido no âmbito do serviço social, que raramente transita na via tecnológica.

Não que a profissão seja atemporal ou que não dialogue com a tecnologia. $\mathrm{O}$ desafio de sua aproximação com os recursos midiáticos e tecnológicos já vem sendo debatido, ainda que pontualmente, há pelo menos duas décadas. Faleiros, em suas obras não poupa comentários sobre a necessidade de o serviço social estreitar seus laços com a tecnologia. Faleiros aponta como desafios ao Serviço Social, no contexto de sua teoria da correlação de forças, portanto, em uma linha emancipatória e crítica de ação profissional, a articulação com as TICs, as redes, os territórios, as culturas, as informações no contexto local e mundial, para consagrar uma produção de conhecimento critico e estratégias de aprofundamento da democracia participativa (Faleiros, 2006).

O fato do site do projeto ser o espaço central de comunicação, coleta de dados e organização de todo o processo investigativo reflete a presença marcante da inovação tecnológica no processo investigativo da pesquisa social.

O projeto, no cenário em que se efetuou a desconstrução mitos e fetichismos associados a uma visão reducionista de tecnologia (situada na crença de um suposto caráter imobilizante, repetitivo, reprodutivista e massificador), permitiu ver o uso das TICs e sua potencialidade, rompendo com as motivações essencialmente dogmáticas que persistentemente tem afastado a profissão do uso dos recursos da tecnologia de informação e comunicação.

Como segundo ponto importante, está a colaboração de todos para o alcance de uma visão atualizada orgânica e crítica da terminologia adotada no pensamento profissional contemporâneo. Esta se pode dizer, sempre foi a essência do projeto. A democratização aludida em todo o processo, compassada pela chamada nacional colaborativa, pela via do concurso cientifico, resultou no empoderamento de sujeitos, no surgimento de novas referências, referenciamentos, potencialidades, assim como na quebra de divisórias de saber/poder, ao investir na criação de um olhar novo, revigorado e crítico sobre os domínios da profissão. E ao fazê-lo, fez-se muito, construiu-se mais que o novo, algo extraordinário em termos de vivência coletiva, de partilha de conhecimento entre os diversos participantes, em um clima de efervescente emancipação, rupturas e superações paradigmáticas. O princípio da Inteligência Coletiva, criada pelo sociólogo Pierre Levy (2000) foi posto em prática.

Não menos importante, como terceiro ponto, é primordial fazermos referência ao conhecimento científico produzido a partir do projeto, diretamente a partir da obra "dicionário" que o sintetiza e, indiretamente, a partir substancial produção cientifica gerada sobre o significado da experiência de conhecimento vivenciada, em que são porta-vozes todos os protagonistas, participantes do concurso, avaliadores convidados, e equipe de bolsistas do projeto e são produtos, os trabalhos apresentados em eventos e os artigos diversos que se debruçaram a refletir sobre essa vivência no projeto e/ou seu contributo à teorização e práxis do serviço social brasileiro.

Essas ações em sua gênese e dinâmica favoreceram que o livro dicionário crítico, resultante do projeto, tivesse a riqueza das análises, baseadas nos trabalhos submetidos, justamente pela pluralidade viabilizada e facilitada pelo uso de tecnologias da informação e comunicação.

Assim considerando, no contexto do conhecimento produzido, não restam dúvidas de que projeto - que intencionou a abastecer os processos de trabalho profissionais e o debate contemporâneo da profissão - alcançou seus objetivos, traduzidos na atualização, ampliação e reconceituação do saber 
profissional efetuados, em que são diretamente beneficiados os assistentes sociais e acadêmicos e, indiretamente, os segmentos mais excluídos, correntemente usuários dos serviços e políticas onde atuam os assistentes sociais.

O projeto teve também outros contributos, igualmente importantes aos anteriormente citados. Referimo-nos ao seu significado nas esferas mais privadas e subjetivas, no universo de quem dele participou.

De fato, para a grande maioria dos sujeitos envolvidos no concurso cientifico participar do projeto, representou não apenas o desenvolvimento de conhecimento sobre o serviço social, mas exponencialmente o despertar, a descoberta e o aprimoramento de habilidades, competências e potencialidades individuais - fosse ele acadêmico, profissional ou membro da equipe do projeto. De fato, não é sempre que se pode protagonizar o processo de construção de uma obra cientifica, sobretudo se ela se constrói a tantas mãos. $\mathrm{Na}$ linguagem marxista, pode-se "ouvir a relva crescer".

Por tudo isso, a pesquisa representou um marco na pesquisa social e no serviço social, ao atender ao que Bachelard (1986) e Kuhn (1978) denominam respectivamente, "novo espírito cientifico" e "revolução paradigmática", ou seja uma nova e critica forma de fazer ciência, em que a construção coletiva e colaborativa de conhecimento, principalmente eliminando sujeições e subvertendo lugares de saber/poder instituídos, é possível.

\section{CONCLUSÕES}

O projeto nasce do sonho e olhar perspectivo de uma professora e torna-se uma construção coletiva, interativa, de âmbito nacional. A problematização individual, ganha corpo coletivo, e atende à necessidade e interesse de muitos; especialmente, servindo às atuais e às novas gerações profissionais. Isso é indescritivelmente gratificante.

Mas, ao se desenvolver o projeto foi além da simples execução de uma proposta científica: representou uma inovação tecnológica e uma revolução cientifica dentro da área do Serviço Social. Em primeiro lugar, inovou-se por usar as TICs, atento à competência técnico-cientifica e condicionantes de qualidade que requisitam, como ferramentas estratégicas em seu desenvolvimento. Em segundo lugar, inovou-se e se revolucionou - em atenção ao convite de T. Kuhn (1978) e G. Bachelard (1986) quando tratam do novo espírito cientifico e da revolução científico-paradigmática - por compor um caminho efetivamente dialógico, coletivo, descentralizado e emancipatório ao propor-se a compor uma obra, a várias mãos (e com as digitais de sujeitos profissionais e acadêmicos, conhecidos ou anônimos, residentes em várias localidades do país, incluindo as historicamente esquecidas ou ignoradas); obra esta não menos do que o primeiro Dicionário da área profissional.

Essa condição e mérito elevaram não só a UFSM como o Projeto no conceito dos profissionais - sobremaneira aos olhos da elite intelectual da área profissional - dando a ele importância, visibilidade e reconhecimento nacional.

A visitação ao site do projeto, veículo de comunicação e difusão principal, foi crescente, atingindo em final de dezembro de 2012 a marca de mais de 2400 visitantes únicos ${ }^{8}$ e, às vésperas do encerramento das inscrições em março de 2013, mais de 4500 visitantes. Essa repercussão é inédita na profissão e expressa a ressonância do projeto na comunidade profissional.

Com a publicação do livro, eterniza-se essa história de pesquisa e trabalho acadêmico, coletivamente tecido. Que bons ventos o levem a diversos territórios de formação profissional, em nível de extensão, graduação e pós-graduação em serviço social, para consagrar sua missão e contributo científicos.

\section{AGRADECIMENTOS}

Compor um projeto dessa dimensão não se faz apenas com boas intenções, nem tampouco solitariamente. O sucesso do projeto deve-se a um corpo de sujeitos essencialmente vivos, ativos e marcantes em todas as fases do projeto os quais, reunidos à coordenadora, contribuíram em sua materialização. Por isso assinalar e agradecer a presença desses sujeitos no projeto é importante.

Tudo tem inicio com a aprovação do projeto na equipe do NTE e da UAB da UFSM. Os professores Elena Malmann, Fábio Purificação de Bastos e Ricardo Dalmolin foram sempre presentes,

\footnotetext{
8 Por visitante único entende-se a contagem de visitante por IP de cada computador e não a "revisita". Assim, cada acesso realizado por um mesmo computador ou notebook é contado apenas uma vez na ocasião do primeiro acesso efetuado. A coordenação do projeto e sua equipe optaram por esse formato para se ter uma aproximação mais fiel do número real de interessados e participantes no projeto. Mas a considerar os relatórios periódicos recebidos do site, tem-se conhecimento de que cada "visitante único" acessou em média 15 vezes o site do projeto ao longo de seus quase 12 meses de duração.
} 
e muitas vezes incansáveis e pacientes, prestando apoiando e orientação, quando solicitados.

À CAPES pelo apoio ao projeto mediante o provimento de bolsa à pesquisadora coordenadora do mesmo, além de afiançar a importância da construção investigativa realizada.

O Centro de Processamento de Dados (CPD) da Universidade Federal de Santa Maria, igualmente. Apesar de contarmos com equipes externas para viabilizar o site principal do projeto e mesmo a plataforma moodle, a implantação de algumas ferramentas requisitaram inúmeras vezes suporte, orientação e informações de acessibilidade. Nesse contexto, os profissionais do $\mathrm{CPD}$, da direção a técnicos, sempre acolheram com atenção e responderam com prontidão as nossas necessidades, não raro em contato direto com as equipes externas, para favorecer o pleno funcionamento do site, hospedado no provedor da Universidade.

O apoio solidário (na linha da responsabilidade social empresarial) da EMPRESA GFARIAS foi marcante em todas as fases de planejamento, desenvolvimento tecnológico e monitoramento da plataforma moodle do projeto, provendo o espaço moodle com suporte e espaço necessário para "rodar" o número de visitações e postagens de trabalhos esperada, sendo decisivo ao sucesso alcançado.

Assim como essa parceria, o sucesso do projeto também deve-se a parceria que estabelecemos com a Editora APPRIS - que assumiu desde o início (nos contatos à época de formulação do projeto) a publicação do livro Dicionário Crítico de Serviço Social, apaixonada pela sua proposta e ineditismo.

A adesão de consultores convidados (a elite intelectual da profissão) para a tarefa de avaliação dos trabalhos (conceituações) recebidos foi especialmente importante e mostrou que estávamos no caminho certo. Igualmente, o apoio de colaboradores na construção do material gráfico do projeto, como sua logomarca, criação do design do site principal e sua apresentação na web.

$\mathrm{O}$ apoio de muitos CRESS (Conselhos Regionais de Serviço Social) na difusão do projeto em seus sites foi especialmente importante e deu legitimidade ao projeto (como uma certificação simbólica) no meio profissional.

Mas de nada bastaria o apoio de cada um destes protagonistas, não fosse a pertença e compromisso ativo da equipe de bolsistas voluntários que se uniram à professora coordenadora. A equipe constituída de 16 bolsistas, todas acadêmicas de serviço social, potenciou e literalmente "deu vida" ao projeto.

Pode-se dizer que cada uma deixou sua nítida marca e contributo no projeto, nesses quase doze meses de inserção visceralmente ativa, entusiasmada e colaborativa. Por conta disso, por serem junto à idealizadora e coordenadora do projeto, a força geradora de tudo o que se fez, vale destacar seus nomes. São elas (em ordem alfabética): Adriana de Fatima Pozzobon, Ana Claudia Carlos, Andressa Baccin Dos Santos, Andressa Marian da Silva, Barbara Mariano, Camila Christine Pavão Borges, Daniela Refatti Simoes, Deile Lopes da Conceição, Emily Victoria Leimann, Fabianne Bandero Hoffling, Graciela Medianeira Rosa Ribeiro, Maiara Regina Porto da Rosa, Michele Aguette Rodrigues, Michiele Fiorin Soares, Samara Peres Dornelles Almeida, Sidimar Ferreira Dutra. A cada um e a todos, parceiros, colaboradores e bolsistas, fica o agradecimento pela jornada partilhada e o sucesso obtido.

\section{REFERÊNCIAS BIBLIOGRÁFICAS}

AMARO, Sarita. 70 anos de Serviço Social no Brasil: tempo de reconhecimento do trabalho profissional. Curitiba: Appris, 2013.

AMARO, Sarita (org). Dicionário Crítico de Serviço Social. Curitiba: Appris, 2013 (no prelo).

BARDIN, Laurence. Análise de conteúdo. Lisboa: Edições 70, 1979.

BACHELARD, Gaston. O novo espirito cientifico. Lisboa: Edições 70, 1986.

FOUCAULT, Michel. A ordem do discurso. Sâo Paulo: Loyola, $8^{a}$ ed. 2002.

. A arqueologia do saber. Rio de Janeiro:

Forense-Universitária, 1987.

Microfisica do poder. $10^{\mathrm{a}}$ ed. Rio de

Janeiro: Graal, 1992a

Genealogia del racismo. Madrid: La Piqueta,

$1992 b$

FALEIROS, Vicente de Paula. Estratégias em serviço social. São Paulo: Cortez, $6^{a}$. ed. 2006. 
FREIRE-MAIA, Newton. O que é ciência. In: Mattos, Fernando. Plano Real - o que é ciência. Cadernos do IFAN, Bragança Paulista: EDUSF, n. 16, 1997.

IAMAMOTO, Marilda Villela. Renovação e conservadorismo no serviço social: ensaios críticos. São Paulo: Cortez, 1992.

, O serviço social na contemporaneIdade: trabatho e formação profissional. 2. ed. São Paulo: Cortez , 1999.

KUHN, Thomas. A estrutura das revoluções cientificas. São Paulo: Perspectiva, 1978.

LEIMANN, Emily Victória; POZZOBON, Adriana; RIBEIRO, Graciela e AMARO, Sarita. Dicionário Crítico de Serviço Social: uma construção coletiva, dialética e colaborativa extraordinária. Resumo apresentado no Salão de Iniciação Cientifica da Pontifica Universidade Católica do Rio Grande do Sul (PUCRS). Porto Alegre-RS, 2012.

LEVY, Pierre. Qu'est-ce que levirtuel. Paris: La Découverte, 1995

A inteligência coletiva: por uma antropologia do ciberespaço. 3. ed. São Paulo: Loyola, 2000.

1998

A inteligência coletiva. São Paulo: Loyola,

MINAYO, M. O desafio do conhecimento: pesquisa qualitativa em saúde. São Paulo: Hucitec, 2000. 7 ed.

MORIN, E.; KERN, A. B. Terra Pátria. Porto Alegre: Sulina, 1995.

MORIN, Edgar. Ciência com consciência. Rio de Janeiro: Bertrand Brasil, 1998.

Os sete saberes necessários à educação do futuro.

São Paulo: Cortez; Brasília, DF: UNESCO,2001.

NETTO, José P. O movimento de reconceituação - 40 anos depois. Serviço Social \& Sociedade - Revista de Serviço Social, São Paulo, a. 26, n. 84, p. 05 - 20, nov. 2005.

PARENTE, André. O hipertextual. Revista Famecos, n. 10, jun, 1999.

SILVA, A. M.; RODRIGUES, M. A.; HOFFLING , F. B ; ALMEIDA, S. P. D.;SEGATTO, F.R ;
AMARO, S.T.A. Serviço social e semiótica: um encontro possível. Trabalho apresentado no XVI Simposio de Ensino Pesquisa e Extensão - SEPE do Centro Universitário Franciscando (UNIFRA), Santa Maria-RS, 2012.

SIMÕES, Daniela Refatti; AMARO, Sarita; . dos; ROSA, Maiara Regina; MARIANO, Barbara; CARLOS, Ana Cláudia. Dicionário critico de serviço social: construção de conceitos fundamentais ao serviço social contemporâneo. Uma experiência de pesquisa extraordinária. Trabalho apresentado na Jornada Acadêmica Integrada - JAI. Universidade Federal de Santa Maria (UFSM), Santa Maria-RS, 2012

TRIVIÑOS, Augusto Nibaldo Silva. Introdução à pesquisa em Ciências Sociais: a pesquisa qualitativa em educação. São Paulo: Atlas, 1987.

YAZBEK, Maria C. \& SILVA, Maria O. S. e. Das origens à atualidade da profissão: a construção da Pós-Graduação em Serviço Social no Brasil. In: CARVALHO, D. B. B. de; SILVA, M. O. S. e (Org.) Serviço Social, Pós-Graduação e produção de conhecimento no Brasil. São Paulo: Cortez, 2005, p. 25 - 49.

WRIGHT, Lisa. MeritsandLimitationsofDistributedLeadership: ExperiencesandUnderstandingsofSchoolPrincipals. CanadianJournalofEducationalAdministrationandPolicy, Issue \#69, February 7, 2008. 